\title{
PLACAS CERÂMICAS CONTENDO LODO DE ETA E CINZA DE CASCA DE ARROZ: CORRELAÇÃO DE SUAS PROPRIEDADES FÍSICO-QUÍMICAS COM SUA MICROESTRUTURA
}

\author{
Antônio R. Petterle ${ }^{\mathrm{a}}$, Gustavo G. Santiago ${ }^{\mathrm{a}}$, Wang Chong ${ }^{\mathrm{a}}$, Luciani Somensi ${ }^{\mathrm{b}}$ e Sílvia M. Tamborim ${ }^{\mathrm{a}, \mathrm{c}, *}$ \\ aUniversidade Federal do Pampa, 97546-550 Alegrete - RS, Brasil \\ bDepartamento de Engenharia Civil, Universidade Federal do Rio Grande do Sul, 90650-001 Porto Alegre - RS, Brasil \\ 'Departamento de Físico-Química, Instituto de Química, Universidade Federal do Rio Grande do Sul, 91501-970 Porto Alegre - \\ RS, Brasil
}

Recebido em 22/04/2018; aceito em 13/08/2018; publicado na web em 18/09/2018

\begin{abstract}
CERAMIC PLATES CONTAINING SLUDGE FROM A WATER TREATMENT PLANT AND THE RICE HUSK ASH: RELATION BETWEEN PHYSICAL-CHEMISTRY PROPERTIES AND MICROSTRUCTURE. Pressed ceramic plates were made from mixtures with different proportions containing kaolinite clay, silica extracted from the rice husk ash after controlled burning at controlled temperature and sludge from a water treatment plant. Physical properties such as density, water absorption and porosity, mechanical properties such as compressive strength, and thermal characteristics such as thermal conductivity of the ceramic plates after burning (DIN EN12667) were evaluated. The silica when inserted in the kaolinite clay can have a gradual increase of its performance, be reduced in the porous phase, with reduction of the thermal conductivity and increase of the mechanical resistance. The use of the sludge from a water treatment plant when incorporated to the ceramic mass is a great number of peaks of charge and of crystallization, expressive increase of porosity and decrease of the thermal and mechanical resistances. As ceramic plates with a trace $72 \%$ kaolinite clay, $18 \%$ rice husk and $10 \%$ sludge from a water treatment plant show lower thermal conductivity $0.2574 \mathrm{~W} \mathrm{~m}^{-1} \mathrm{~K}^{-1}$, and a higher compressive strength of $172.12 \mathrm{MPa}$ when compared to the other plates tested where the substitutions for sludge from a water treatment plant occurred.
\end{abstract}

Keywords: rice husk ash; sludge from a water treatment plant; ceramic plates.

\section{INTRODUÇÃO}

Em princípio, toda atividade industrial e agroindustrial produz resíduos, classificados conforme normas específicas para cada atividade, que podem ser tóxicos e perigosos. O descarte destes produtos com prejuízo ao meio ambiente e à sociedade como um todo não é permitido e é definido como crime ambiental. ${ }^{1}$

Diversos estudos estão sendo desenvolvidos para avaliar os efeitos da adição e/ou substituição de resíduos na produção de cerâmicas.

O estado do Rio Grande do Sul é o principal produtor de arroz irrigado do Brasil. Conforme dados do IRGA safra 2016/17, a produção foi de $8.746 .825 \mathrm{t}$ do cereal. ${ }^{2}$

Desta produção, $23 \%$ em peso corresponde à casca de arroz (CA), um resíduo que possui alto poder calorífico $\left(16720 \mathrm{~kJ} \mathrm{~kg}^{-1}\right) \mathrm{e}$, portanto, apresenta alto potencial como fonte alternativa de energia térmica. Em razão disto, indústrias de beneficiamento utilizam a mesma para a secagem do próprio cereal. ${ }^{3}$

De acordo com dados da Aneel, existem no Rio Grande do Sul nove unidades termoelétricas produtoras de energia que utilizam como fonte de calor a biomassa da casca do arroz, entre essas, duas no Município de Alegrete: A GEEA - Geradora de Energia Elétrica Alegrete Ltda empresa do grupo Pilecco Nobre e a UTECAAL - Unidade Termoelétrica Empresa da Cooperativa Agroindustrial Alegrete Ltda.

Como resultado do aproveitamento da CA, tem-se também a geração de um novo resíduo, a cinza da casca do arroz (CCA), que, quando queimada com temperatura de combustão controlada, apresenta grande quantidade de sílica amorfa e elevado grau de pureza. ${ }^{4}$ Desta forma, e também considerando os efeitos nocivos ao meio ambiente no ato de simplesmente descartar este material a céu aberto,

*e-mail: silvia.tamborim@ufrgs.br ocorrem inúmeros esforços para o reaproveitamento desses resíduos gerados como, por exemplo: $:^{5-15}$

- Inserção no traço do concreto armado para fins de aumento da resistência mecânica em substituição ao cimento ${ }^{6,7}$ ou até mesmo para fins anticorrosivos; ${ }^{4}$

- Reagente para a síntese de filamentos de $\mathrm{SiC}^{8}{ }^{8}$

- Precursor para a produção de zeólitas; ${ }^{9}$

- Adsorventes para chumbo e mercúrio em água residuárias; ${ }^{10,11}$ As indústrias de tratamento de água do Brasil transformam a água bruta, normalmente inadequada para o consumo humano, em água potável através de estações de tratamento de água (ETAs).

As ETAs podem ser vistas como mini-fábricas de resíduos, na faixa de 5\% do volume total de água tratada, que corresponderia à geração de 5 milhões de toneladas de lodo residual por ano. ${ }^{16}$

Os principais processos utilizados em ETAs são: coagulação, floculação, decantação e filtração. Durante esses processos, adicionam-se vários produtos químicos, como: sulfato de alumínio, sulfato de ferro, hidróxido de cálcio e cloro. Esses sistemas de tratamento de água geram um resíduo denominado lodo de estação de tratamento (LETA), e é originado, na maioria das vezes, na fase de decantação e filtração. ${ }^{17}$

O LETA gerado no decantador é um material rico em $\mathrm{SiO}_{2}$, $\mathrm{Al}_{2} \mathrm{O}_{3}$ e $\mathrm{Fe}_{2} \mathrm{O}_{3}$.

Do ponto de vista mineralógico, é constituído de caulinita, mica, sílica e gibsita, com predominância de caulinita. O resíduo apresenta morfologia irregular das partículas e larga distribuição de tamanho de partículas, entre 1 até $425 \mu \mathrm{m}$.

Segundo a Norma ABNT NBR 10004/87, ${ }^{18}$ o lodo de ETA é um material classificado como rico em argilominerais, silte e areia, sendo classificado como resíduo classe IIA não inerte por possuírem normalmente contaminantes químicos e concentrações de sólidos maiores que $2,5 \mu \mathrm{m}$. 
Devido à sua composição química, o LETA é considerado um resíduo sólido não inerte que necessita de uma disposição final adequada, porém, o seu destino na maioria das vezes são os corpos d'água mais próximos. ${ }^{19}$

O reaproveitamento do LETA tem sido desenvolvido nas mais diversas áreas, principalmente na fabricação de cimentos e na produção de cerâmicas, em função de altas concentrações de aluminio, sílica e óxido de ferro.

Neste sentido, as indústrias de construção civil têm auxiliado bastante no reaproveitamento destes materiais, como, por exemplo:

- Reaproveitamento do LETA na produção de tijolos cerâmicos; ${ }^{20}$

- Produção de cerâmica vermelha com LETA; ${ }^{21}$

- Reaproveitamento do LETA na produção do cimento Portland;22 Entretanto, dependendo das quantidades de alguns metais, como cobre, zinco, níquel, chumbo, cádmio, cromo, manganês e, em especial, alumínio presentes no LETA, que possuem ações tóxicas, podem apresentar efeitos nocivos ao homem e até impedir a sua reutilização..$^{22,23}$

Considerando todos os esforços e pesquisas contemplando o reaproveitamento de materiais a fim de minimizar os impactos ambientais a partir de fontes inócuas, o objetivo do presente trabalho é aliar às propriedades da sílica amorfa, como sua baixa condutividade térmica e estabilidade dimensional, o efeito estabilizador de fase do LETA que apresenta na composição química elevados teores de alumina. Desta forma, propõem-se o desenvolvimento de placas cerâmicas visando o estudo do desempenho termomecânico baseado no desenvolvimento das fases em equilíbrio formadas nos diferentes traços das misturas: argila caulim: CCA: LETA.

\section{MATERIAIS E MÉTODOS}

Como matérias-primas, foram utilizadas a argila caulim, adquirida da empresa Helager Indústria e Comércio Ltda, a sílica da casca de arroz, fornecida pela empresa Sílica Verde do Arroz LTDA, e o lodo de ETA, coletado na estação de tratamento de águas da cidade de Alegrete/RS.

\section{Caracterização das Matérias-primas}

\section{Sílica da casca de arroz.}

A sílica utilizada no desenvolvimento deste trabalho foi produzida pelo processo de geração de energia através da queima casca de arroz com temperatura controlada. Essa sílica é obtida através da combustão da casca de arroz em leito fluidizado e seu processo de obtenção conta com um sistema de automação no intervalo de temperatura entre 600 ${ }^{\circ} \mathrm{C}$ e $700{ }^{\circ} \mathrm{C}$, que permite a extração da sílica da casca de arroz com estrutura predominantemente amorfa.

Análises de fluorescência de raios X da sílica extraída da casca de arroz foram realizadas em um equipamento Philips, modelo PW 2400 , com tubo de $3 \mathrm{~kW}$ e alvo de ródio. Foram usados os procedimentos de operação do equipamento e as normas NBR $9644^{24}$ e NBR 128601.25

A Tabela 1 mostra que o principal constituinte da sílica da casca de arroz utilizada é o óxido de silício $(91,48 \%)$ e óxidos fundentes, tais como os óxidos de cálcio $(0,36 \%)$ e potássio $(1,40 \%)$, os quais ocorrem em quantidades extremamente baixas, mas que possibilitam durante a sinterização a formação de fase vítrea. $\mathrm{O}$ valor de perda ao fogo de $3,50 \%$ se deve ao elevado carbono residual presente. Tal situação indica a necessidade de observação da temperatura de obtenção das cinzas tendo em vista que estas definem a quantidade de carbono residual, além de estudos prévios indicarem uma redução considerável deste a $1100{ }^{\circ} \mathrm{C} .{ }^{26}$

Análises de CHN da sílica da casca de arroz do lote utilizado
Tabela 1. Composição química da sílica da casca de arroz (\% massa)

\begin{tabular}{cc}
\hline Elementos químicos & $\%$ massa \\
\hline $\mathrm{SiO}_{2}$ & 91,48 \\
$\mathrm{CaO}$ & 0,36 \\
$\mathrm{MgO}$ & 0,32 \\
$\mathrm{Fe}_{2} \mathrm{O}_{3}$ & 0,05 \\
$\mathrm{Al}_{2} \mathrm{O}_{3}$ & $\mathrm{ND}$ \\
$\mathrm{Na}_{2} \mathrm{O}$ & 0,04 \\
$\mathrm{~K}_{2} \mathrm{O}$ & 1,40 \\
$\mathrm{TiO}_{2}$ & 0,003 \\
$\mathrm{MnO}$ & 0,32 \\
$\mathrm{SO}_{3}$ & 0,15 \\
$\mathrm{P}_{2} \mathrm{O}_{5}$ & 0,45 \\
Perda ao fogo & 3,50 \\
\hline
\end{tabular}

apresentaram uma quantidade média ( $\%$ massa) de 2,05\% de carbono, $0,02 \%$ de hidrogênio e $0,06 \%$ de nitrogênio.

$\mathrm{O}$ equipamento utilizado para realização de difração de raios $\mathrm{X}$ foi um difratômetro Rigaku, modelo Ultima IV, com radiação $\mathrm{K} \alpha$, potência de $45 \mathrm{kV}$ e corrente de $40 \mathrm{~mA}$. As análises foram realizadas em amostras na forma de pó, sem nenhum tipo de preparação prévia, no intervalo de medida de $2 \theta$ entre 0 e $75^{\circ}$. Conforme a Figura 1, o difratograma da SCA indica uma estrutura tipicamente amorfa. Os picos associados à presença de espécies cristalinas $\left(20,85^{\circ}\right.$ e $\left.36,01^{\circ}\right)$ são atribuídos a contaminações do material inerte utilizado, ou seja, areia, sílica cristalina na forma de quartzo, necessária para desenvolver o processo de fluidização da casca de arroz.

Angel et al. ${ }^{27}$ Armesto et al. ${ }^{28}$ e Rozainee et al. ${ }^{29}$ também atribuíram a presença de cristais de quartzo, na cinza, ao arraste da areia para fora do reator na combustão de cinza da casca de arroz em leito fluidizado borbulhante e atmosférico.

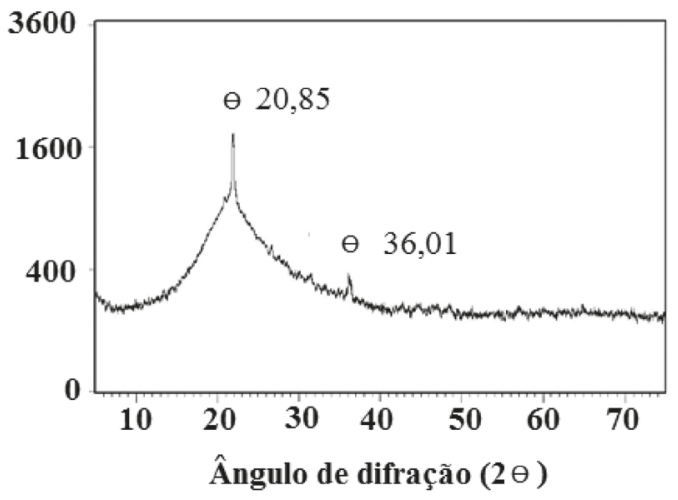

Figura 1. Difratograma da sílica da casca de arroz.

Os resultados da distribuição granulométrica da sílica da casca de arroz foram obtidos por granulometria a laser e estão mostrados na Figura 2. Os constituintes apresentam tamanhos de grãos muito variados, com um diâmetro médio de grãos em torno $13 \mathrm{~mm}$, predominando a presença de grandes grãos.

A Figura 3 mostra a imagem de microscopia eletrônica de varredura da sílica da casca de arroz utilizada, a qual apresenta uma polidispersão bastante variada tanto na geometria quanto no tamanho dos grãos.

\section{Argila caulim}

A argila caulim utilizada foi analisada por fluorescência de raios X e a análise mostrada na Tabela 2, segundo a classificação da NBR $10237,{ }^{30}$ a classifica como silicoaluminosa. A argila caulim utilizada 


\section{Curva Granulométrica}

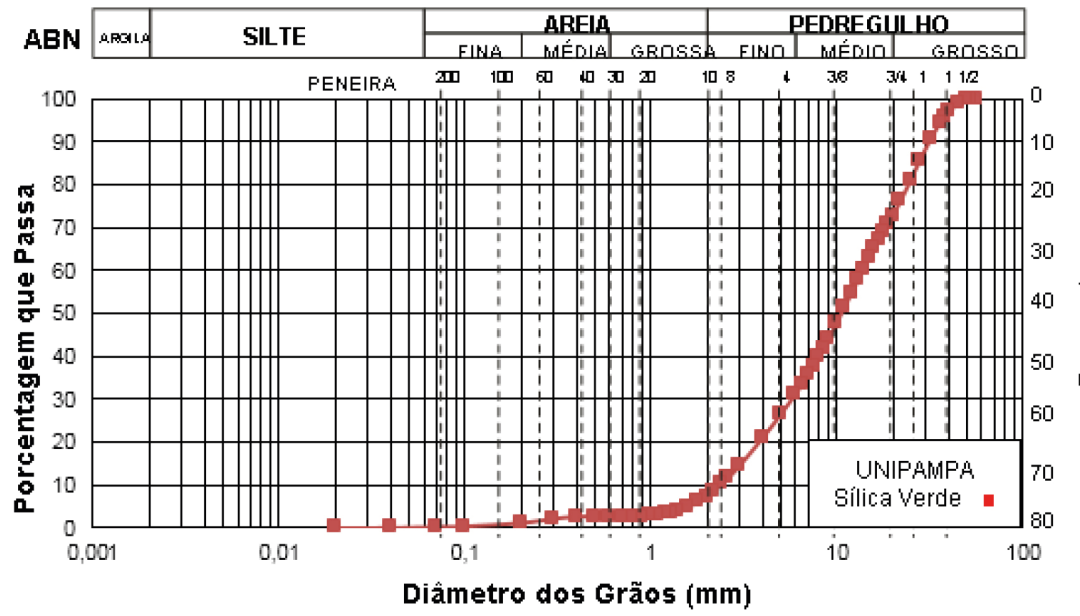

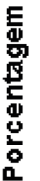

Figura 2. Distribuição granulométrica da sílica da casca de arroz

(A)

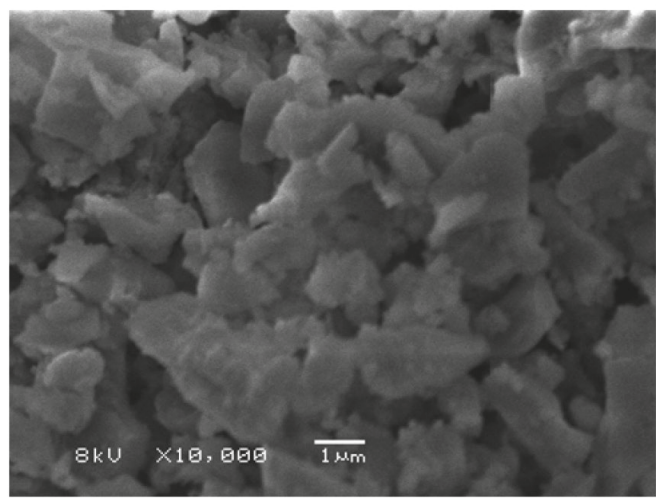

(B)

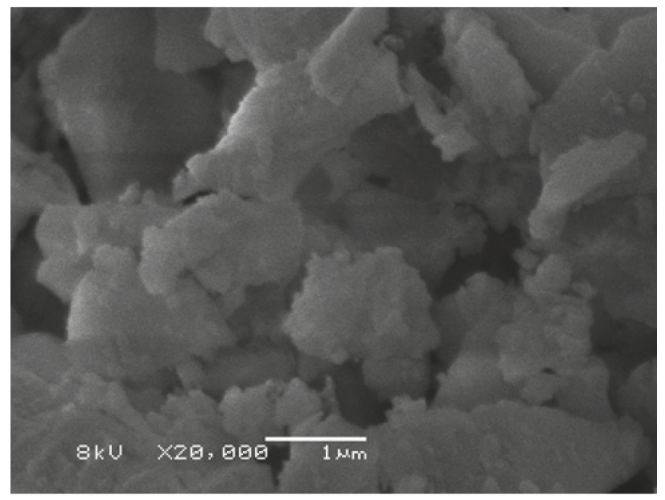

Figura 3. Microscopia eletrônica de varredura da sílica da casca de arroz utilizada

é constituída basicamente por óxido de silício (57.83\%), alumina (27.52\%), por óxidos fundentes, como óxido de ferro $(2.25 \%) \mathrm{e}$ óxido de potássio (1.87\%), o qual é um bom formador de fase vítrea. Apresenta perda ao fogo de $8.63 \%$, provavelmente pela presença de compostos orgânicos. Análises de $\mathrm{CHN}$ da argila caulim utilizada apresentaram quantidades mássicas médias de 0,24\% de carbono, $0,49 \%$ de hidrogênio e $0,12 \%$ de nitrogênio.

Tabela 2. Composição química da argila caulim (\% massa)

\begin{tabular}{cc}
\hline Elementos & $(\%$ massa $)$ \\
\hline $\mathrm{SiO}_{2}$ & 57,83 \\
$\mathrm{CaO}$ & 0,13 \\
$\mathrm{MgO}$ & 0,36 \\
$\mathrm{Fe}_{2} \mathrm{O}_{3}$ & 2,25 \\
$\mathrm{Al}_{2} \mathrm{O}_{3}$ & 27.52 \\
$\mathrm{Na}_{2} \mathrm{O}$ & $<0,001$ \\
$\mathrm{~K}_{2} \mathrm{O}$ & 1,87 \\
$\mathrm{TiO}_{2}$ & 0,38 \\
$\mathrm{MnO}$ & $<0,01$ \\
$\mathrm{SO}_{3}$ & - \\
$\mathrm{P}_{2} \mathrm{O}_{5}$ & - \\
$\mathrm{Perda} \mathrm{ao} \mathrm{fogo}$ & 8,63 \\
\hline
\end{tabular}

A análise de infravermelho da argila caulim mostrada na Figura 4 confirma a composição com bandas referentes à presença de sílica, alumina, caulinita e ilita, conforme as vibrações especificadas na Tabela 3.

A análise da composição mineralógica da argila caulim por

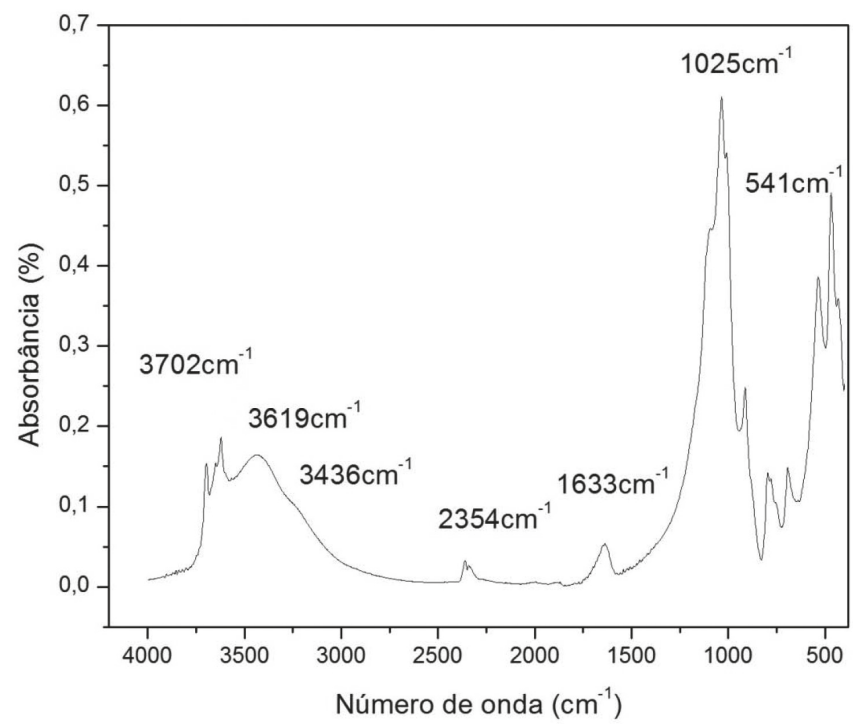

Figura 4. Espectroscopia do infravermelho da argila caulim 
Tabela 3. Bandas da espectroscopia de infravermelho da argila caulim

\begin{tabular}{|c|c|}
\hline Número de onda $\left(\mathrm{cm}^{-1}\right)$ & Bandas de vibração \\
\hline $3693,3669,3651,3619$ & Hidroxílas da superfície interna ligada a $\mathrm{Al}^{+3}$ \\
\hline 3443 & $\begin{array}{l}\text { Banda larga referente ao estiramento da água } \\
\text { de hidratação em minerais argilosos como ílita } \\
\text { e caulinita }\end{array}$ \\
\hline 1638 & Deformação angular de água de hidratação \\
\hline 1382 & Impurezas carbonato ou sulfato \\
\hline 1119 & $\begin{array}{l}\text { Vibração Si-O apical comum nas argilas ilita } \\
\text { e caulinita }\end{array}$ \\
\hline 1031 e 1009 & Vibração de estiramento Si-O-Si \\
\hline 938 & $\begin{array}{c}\text { Deformação angular da superfície interna de } \\
\text { Al-O-H }\end{array}$ \\
\hline 796 e 757 & Deformação translacional do grupamento $\mathrm{O}-\mathrm{H}$ \\
\hline 695,471 e 432 & Deformação angular Si-O \\
\hline 539 & Deformação angular Si-O-Al \\
\hline
\end{tabular}

difração de raios $\mathrm{X}$ na Figura 5 mostra que o quartzo se destaca como o principal constituinte $\left(2 \theta=27,5^{\circ}\right)$, a caulinita como constituinte secundário $\left(2 \theta=12^{\circ}\right.$ e $\left.25^{\circ}\right)$ e um pequeno pico de montmorilonita $\left(2 \theta=18^{\circ}\right)$, mineral provavelmente resultante das reações entre os componentes químicos $\mathrm{Ca}, \mathrm{Mg}, \mathrm{Al}$ e $\mathrm{Na}$ de origem sedimentar.

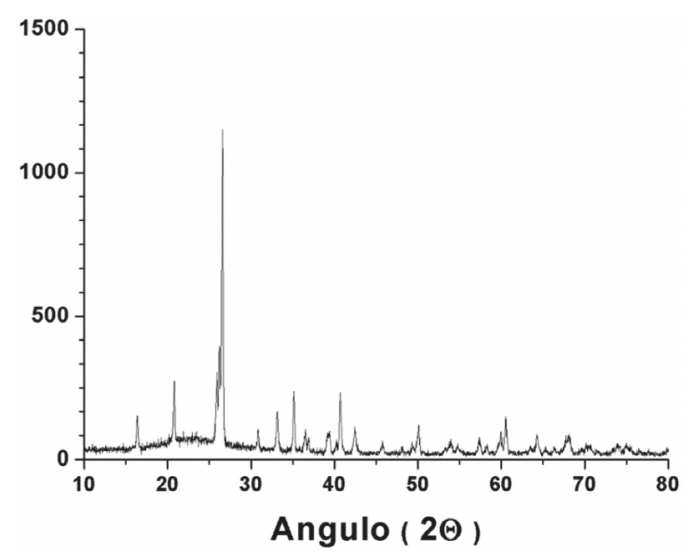

Figura 5. Difratograma da argila caulim utilizada
O ensaio granulométrico da argila caulim, Figura 6, foi realizado por peneiramento e sedimentação seguindo as orientações da NBR $7181 .{ }^{31}$

A distribuição granulométrica da argila caulim apresentou aproximadamente $3,2 \%$ de areia, formada por minerais e/ou partículas de rochas com diâmetros compreendidos entre $0,06 \mathrm{~mm}$ e $0,8 \mathrm{~mm}$. Observa-se a predominância do silte $(75,67 \%)$, formado por partículas com diâmetros compreendidos entre $0,002 \mathrm{~mm}$ e $0,06 \mathrm{~mm}$, e a argila $(21,13 \%)$ possui graduação fina constituída por partículas com dimensões menores que $0,002 \mathrm{~mm}$.

As imagens de microscopia eletrônica de varredura da argila caulim mostrada na Figura 7 confirmam o perfil arenoso de granulometria fina apresentado pela curva granulométrica.

\section{Lodo de estação de tratamento de água}

A análise de fluorescência de raios X mostrada na Tabela 4 confirma que o lodo de ETA é um composto sílicoaluminoso constituído basicamente por de óxido de silício $(36,11 \%)$, na forma de quartzo, alumina $(32,31 \%)$, óxido de ferro $(18,58 \%)$, óxido de magnésio $(0,48 \%)$, óxido de cálcio $(0,42 \%)$, formadores de fase vítrea além de constituintes residuais que despertam interesse da indústria cerâmica. Apresenta perda ao fogo de aproximadamente $16,88 \%$ pela presença da caulinita e matéria orgânica. As análises de $\mathrm{CHN}$ do lodo utilizado apresentaram $6,77 \%$ de carbono, $2,21 \%$ de hidrogênio e $0,58 \%$ de nitrogênio.

A análise de espectroscopia na região do infravermelho com transformada de Fourier (FT- IR) do lodo ETA indicou picos característicos das fases cristalinas referentes à caulinita $\left(\mathrm{Al}_{2} \mathrm{O}_{3} \cdot 2 \mathrm{SiO}_{2} \cdot 2 \mathrm{H}_{2} \mathrm{O}\right)$, sílica $\left(\mathrm{SiO}_{2}\right)$, gibsita $\left(\mathrm{Al}(\mathrm{OH})_{3}\right)$, hematita $\left(\mathrm{Fe}_{2} \mathrm{O}_{3}\right)$, goethita $(\mathrm{FeO}(\mathrm{OH}))$, moscovita $\left(\mathrm{KAl}_{3} \mathrm{Si}_{3} \mathrm{O}_{10}(\mathrm{OH})_{2}\right)$ e rutilo $\left(\mathrm{TiO}_{2}\right)$, dentre outros.

A Figura 8 mostra a espectroscopia de infravermelho do lodo do ETA com os grupamentos mineralógicos destacados.

A granulometria do lodo de ETA, Figura 9, foi realizada por peneiramento e sedimentação, seguindo orientações da NBR 7181.31 $\mathrm{O}$ resultado de granulometria do lodo de ETA permitiu concluir que a areia $(71,12 \%)$ é formada por minerais ou partículas de rochas com diâmetros compreendidos entre $0,02 \mathrm{~mm}$ e $0,8 \mathrm{~mm}$, o silte $(22,15 \%)$ é formado por partículas com diâmetros compreendidos entre 0,002 $\mathrm{mm}$ e $0,06 \mathrm{~mm}$ e a argila $(6,73 \%)$ possui graduação fina constituída por partículas com dimensões menores que $0,002 \mathrm{~mm}$.

Conforme do diagrama de Winkler ${ }^{31}$ podemos observar que o lodo de ETA utilizado pode ser classificado como um lodo arenoso.

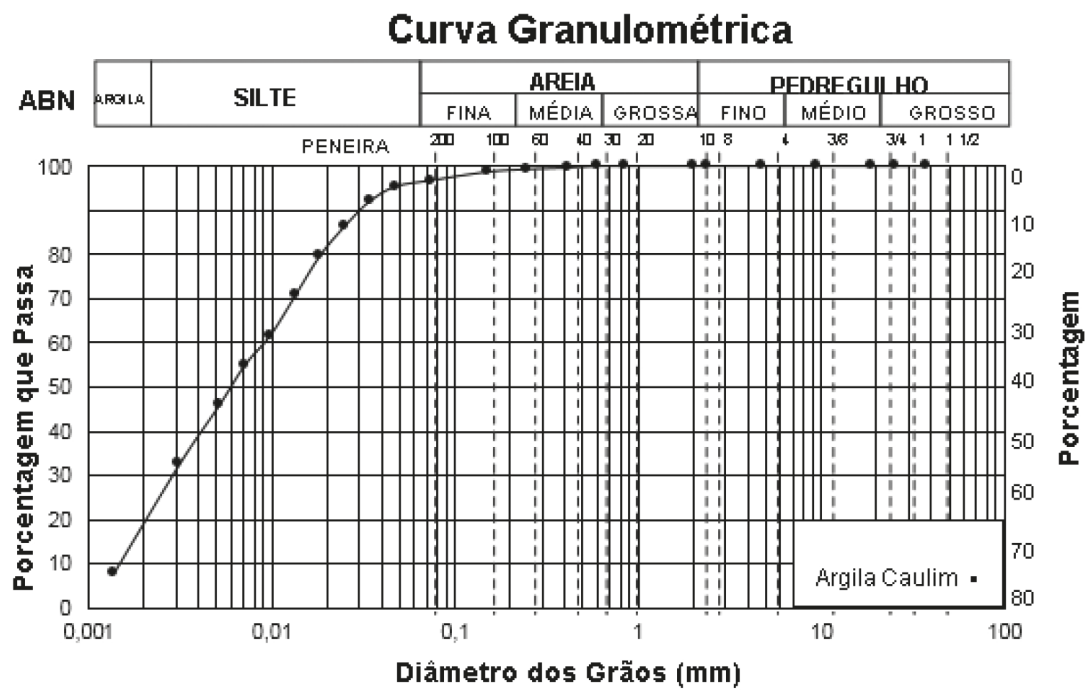

Figura 6. Distribuição granulométrica da argila caulim 
(A)

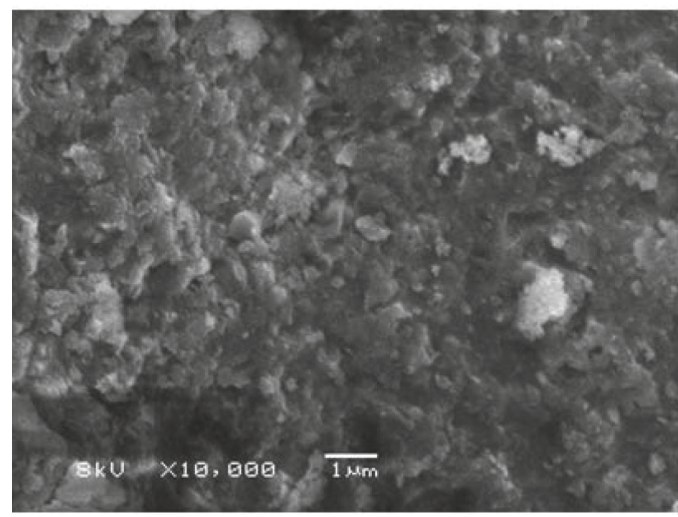

Figura 7. Microscopia eletrônica de varredura da argila caulim

Tabela 4. Composição química do lodo de estação de tratamento de águas (\% massa)

\begin{tabular}{cc}
\hline Elementos químicos & $\%$ massa \\
\hline $\mathrm{SiO}_{2}$ & 36,11 \\
$\mathrm{CaO}$ & 0,42 \\
$\mathrm{MgO}$ & 0,48 \\
$\mathrm{Fe}_{2} \mathrm{O}_{3}$ & 11,58 \\
$\mathrm{Al}_{2} \mathrm{O}_{3}$ & 32,31 \\
$\mathrm{Na}_{2} \mathrm{O}$ & 0,03 \\
$\mathrm{~K}_{2} \mathrm{O}$ & 0,55 \\
$\mathrm{TiO}_{2}$ & 1,02 \\
$\mathrm{MnO}$ & 0,07 \\
$\mathrm{SO}_{3}$ & $\mathrm{ND}$ \\
$\mathrm{P}_{2} \mathrm{O}_{5}$ & 0,35 \\
$\mathrm{Perda}$ ao fogo & 16,88 \\
\hline
\end{tabular}

A morfologia de granulação bastante refinada comparada a outros lodos de estação de tratamento ${ }^{32}$ é perceptível também pela imagem de microscopia eletrônica de varredura mostrada na Figura 10 com 10000 (A) e 20000 (B) vezes de aumento.

A perda ao fogo do lodo de ETA é de 16,88\% (Tabela 4) e, portanto, o somatório de perda ao fogo dos constituintes é bastante
(B)

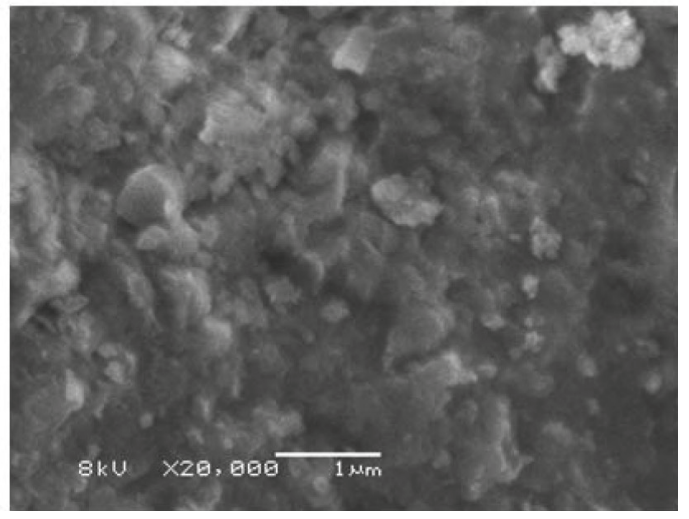

Figura 8. Espectroscopia do infravermelho do lodo de estação de tratamento (LETA)

elevado, chegando a $29,01 \%$, uma vez que a sílica da casca de arroz e a argila caulim apresentam perda ao fogo de $3,5 \%$ (Tabela 1) e $8,63 \%$ (Tabela 2), respectivamente. Este dado é compatível com as prováveis baixas temperaturas na obtenção e beneficiamento destas

\section{Curva Granulométrica}

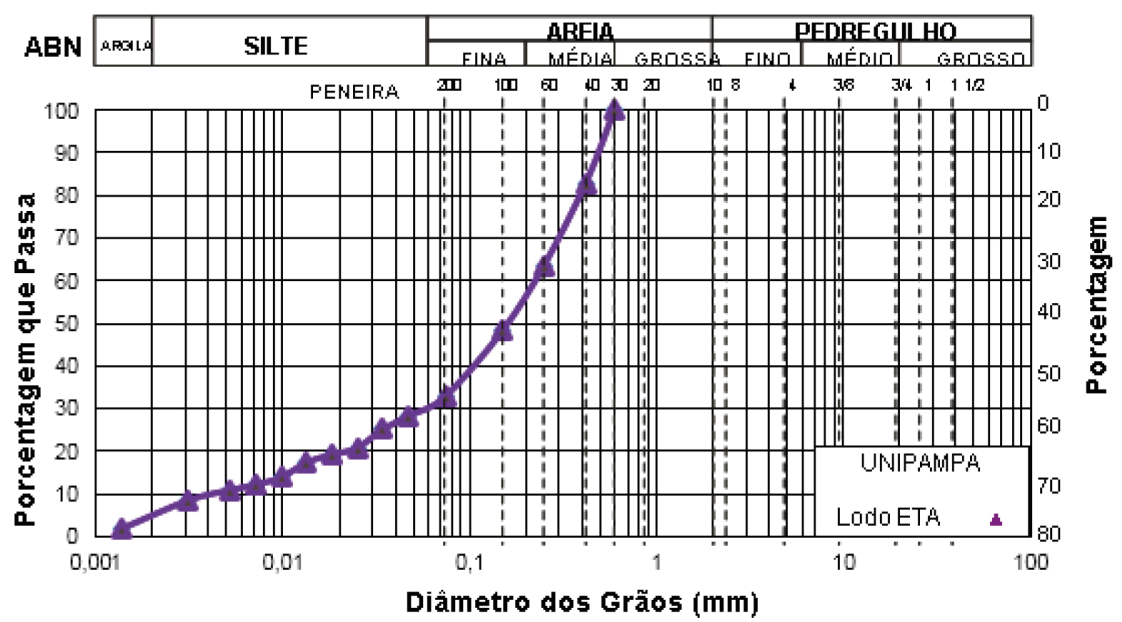

Figura 9. Distribuição granulométrica do lodo de ETA 
(A)

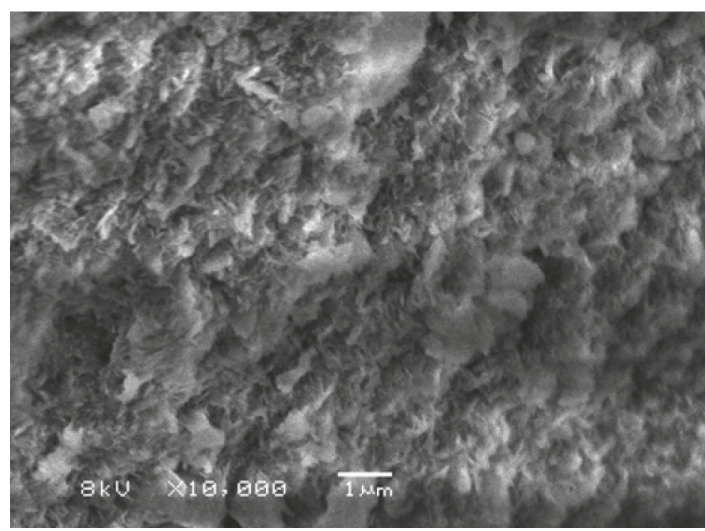

(B)

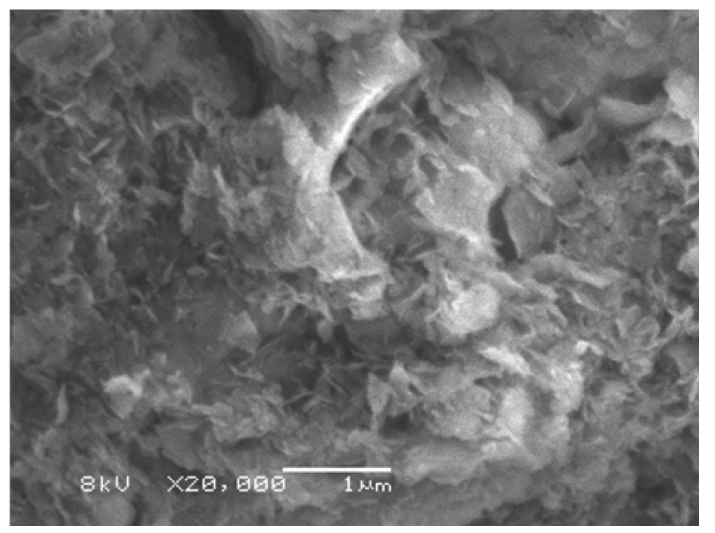

Figura 10. Microscopia eletrônica de varredura do lodo de estação de tratamento

matérias primas. Nesse sentido, quando adicionados e/ou substituídos na massa cerâmica e submetidos a tratamento térmico, proporcionam a formação de poros, provavelmente, pela presença de argilominerais, hidróxidos e matéria orgânica.

\section{Procedimento experimental}

As placas cerâmicas foram obtidas por prensagem uniaxial, a partir de diferentes percentuais de mistura da sílica obtida a partir da queima com temperatura controlada da casca de arroz, lodo de ETA e argila caulim.

Os critérios básicos determinantes para a escolha do desenvolvimento das placas cerâmicas com o objetivo de avaliar o desempenho térmico foram investigados. Os melhores resultados no desempenho de propriedades mecânicas e térmicas foram obtidos quando utilizados diversos traços de substituição desses resíduos em uma massa cerâmica.

As seis formulações testadas para as massas cerâmicas (Tabela 5) foram: $100 \%$ argila caulim (AC) e $80 \%$ de argila caulim e $20 \%$ de sílica (AC20), sendo esta ultima considerada como uma mistura de referência. As demais formulações testadas foram realizadas através de substituições parciais na mistura de referência por lodo de ETA em teores de 10\% (AC20/10), 20\% (AR20/20) e 30\% (AR20/30), sendo essas quantidades determinadas em massa. Uma mistura na ausência da argila caulim contendo 50\% de sílica e 50\% de lodo de ETA foi testada para fim de ensaios comparativos, sendo denominada como SL 50/50.

Tabela 5. Formulações das misturas para as placas cerâmicas (\% massa)

\begin{tabular}{cccc}
\hline Argila Caulim $(\%)$ & Sílica $(\%)$ & Lodo ETA $(\%)$ & Sigla \\
\hline 100 & 0 & 0 & AC \\
80 & 20 & 0 & AC20 \\
72 & 18 & 10 & AC20/10 \\
64 & 16 & 20 & AC20/20 \\
56 & 14 & 30 & AC20/30 \\
0 & 50 & 50 & SL 50/50 \\
\hline
\end{tabular}

Todos os constituintes foram previamente secos em estufa na temperatura de $110 \pm 10{ }^{\circ} \mathrm{C}$ por $24 \mathrm{~h}$ e, após, foram realizadas as misturas pré-determinadas para cada uma das massas cerâmicas. As mesmas foram homogeneizadas por um período de $10 \mathrm{~min}$ com auxílio de um misturador mecânico tipo planetário, ocorrendo a adição de $12 \%$ de água em relação ao valor total de massa.
Posteriormente, o material foi acondicionado em recipientes plásticos vedados por um período de $24 \mathrm{~h}$ para assegurar uma hidratação homogênea.

As placas cerâmicas foram prensadas no formato quadrado por uma matriz macho-fêmea com dimensões de $135 \mathrm{~mm}$ x $135 \mathrm{~mm}$ através da aplicação de uma pressão de compactação de $300 \mathrm{~kg} \mathrm{~cm}^{-2}$. A quantidade de massa requerida para cada molde foi determinada para que as placas tivessem espessura aproximada de $15 \mathrm{~mm}$. Para o ensaio de resistência à compressão foi moldado bloco cúbico com dimensões aproximadas de $25 \mathrm{~mm}$.

Após conformação, os corpos-de-prova foram lavados e secos em estufa na temperatura de $110 \pm 10^{\circ} \mathrm{C}$ por $24 \mathrm{~h}$.

Após a secagem, os corpos de prova foram sinterizados à temperatura de $1300{ }^{\circ} \mathrm{C}$. Definiu-se o ciclo de queima com três patamares: no primeiro patamar foi utilizada uma taxa de aquecimento de $5^{\circ} \mathrm{C}$ $\min ^{-1}$ até a temperatura de $150^{\circ} \mathrm{C}$, onde permaneceu por $10 \mathrm{minu}$ tos para eliminação da umidade superficial. No patamar seguinte a taxa de aquecimento foi de $3{ }^{\circ} \mathrm{C} \mathrm{min}^{-1}$ até a temperatura de 500 ${ }^{\circ} \mathrm{C}$, onde permaneceu por mais 10 minutos para eliminação dos gases originados da combustão e reações do material. No terceiro patamar a taxa de aquecimento foi de $5{ }^{\circ} \mathrm{C} \min ^{-1}$ até a temperatura de $1300{ }^{\circ} \mathrm{C}$, permanecendo neste patamar por 30 minutos. $\mathrm{O}$ resfriamento foi feito de forma natural dentro do forno após o seu desligamento. ${ }^{33}$

Os ensaios para caracterização física do material foram realizados por procedimentos laboratoriais de acordo com a normativa NBR 6220/11, ${ }^{34}$ densidade de massa aparente, porosidade aparente e absorção de água. $\mathrm{O}$ ensaio de resistência à compressão foi realizado seguindo as orientações da NBR 6224/01. ${ }^{35}$ A investigação da microestrutura das placas cerâmicas obtidas foi realizada através da microscopia eletrônica de varredura (MEV).

$\mathrm{O}$ método de difração de raios $\mathrm{X}$ foi utilizado para identificar as fases existentes e as transformações ocorridas após os materiais serem submetidos ao processo de sinterização.

Para determinação da condutividade térmica das placas cerâmicas foi utilizado o método de fluxo de calor em regime estacionário, norma DIN EN12667, ${ }^{36}$ usando-se equipamento da LaserComp modelo 304. A média do fluxo de calor é usada para calcular a condutividade térmica $(\lambda)$ e resistência térmica $(\mathrm{R})$, de acordo com a Lei de Fourier conforme a Equação 1.

$$
\lambda=\frac{Q}{A} \frac{L}{\Delta T}
$$

$\lambda=$ condutividade térmica $\left[\mathrm{W} \mathrm{m} \mathrm{m}^{-1} \mathrm{~K}^{-1}\right] ; \mathrm{Q}=$ quantidade de calor transmitida $[\mathrm{J}] ; \mathrm{A}=$ área $\left[\mathrm{m}^{2}\right] ; \mathrm{L}=$ espessura $[\mathrm{m}] ; \Delta \mathrm{T}=$ diferença na transferência de temperatura entre as placas $[\mathrm{K}]$. 


\section{RESULTADOS E DISCUSSÃO}

\section{Propriedades físicas e mecânicas}

A Tabela 6 apresenta os resultados dos ensaios de absorção de água, porosidade aparente, densidade de massa aparente, resistência à compressão e condutividade térmica das placas cerâmicas estudadas. A adição de sílica da casca de arroz proporciona uma diminuição na absorção de água (de 4,92\% $\pm 0,37$ para 3,93\% $\pm 0,32 \%$ ), na porosidade aparente (de $11,31 \% \pm 5,2$ para $8,9 \% \pm 3,1 \%)$ e na condutividade térmica (de 0,2368 $\pm 0,006 \mathrm{~W} \mathrm{~m}^{-1} \mathrm{~K}^{-1}$ para $0,2258 \pm 0,002 \mathrm{~W} \mathrm{~m}^{-1} \mathrm{~K}^{-1}$ ).

A substituição na mistura AC20 por $10 \%$ lodo de estação de tratamento (AC20/10) gerou um acréscimo de $19,10 \%$ na porosidade e de $20,10 \%$ na absorção de água, enquanto na substituição por $20 \%$ lodo de ETA (AC20/20) o aumento na porosidade foi de 49,66\% e a absorção de água de $59,03 \%$, enquanto que a placa cerâmica com $30 \%$ de lodo ETA (AC20/30) mostrou um aumento de 58,53\% na porosidade e de $69,21 \%$ na absorção de água. Estes resultados são compatíveis com a quantidade de matéria orgânica elevada no lodo de estação de tratamento (Tabela 4). A placa cerâmica AC50/50 apresentou problemas de falta de estabilidade microestrutural, degradação espontânea e se tornou muito suscetível à erosão, impossibilitando que a mesma fosse estudada nas mesmas condições que as demais placas. As placas cerâmicas AC20/10 e SL50/50, conforme Tabela 6, apresentaram resultados de condutividade térmica com valores bastante semelhantes: $0,2574 \mathrm{~W} \mathrm{~m}^{-1} \mathrm{~K}^{-1}$ e $0,2544 \mathrm{~W} \mathrm{~m}^{-1} \mathrm{~K}^{-1}$, respectivamente, entretanto, desenvolveram propriedades microestruturais totalmente diferentes. A resistência média à compressão variou de 172,12 MPa na mistura AC20/10 para 4,92 MPa na mistura SL50/50, assim como a densidade média variou de $2,23 \mathrm{~g} / \mathrm{m}^{3}$ para $1,09 \mathrm{~g} / \mathrm{m}^{3}$, respectivamente, conforme Tabela 6 .

A condutividade térmica dos materiais cerâmicos ocorre basicamente pela vibração da rede cristalina (transporte de calor por fônons). O coeficiente de transmissão térmico de um corpo cerâmico está relacionado diretamente com as fases presentes em sua microestrutura.

A redução de 4,87\% nos índices de condutividade térmica nas placas AC20 provavelmente é devido à composição química destas placas. É possível visualizar pelos gráficos de difração de raios $\mathrm{X}$ da Figura 11 (a) e (b) que as placas AC20 mostram uma intensificação da fase vítrea referente a presença de cristobalita $(2 \theta=21,75)$, mulita $(2 \theta=50,00)$ e quartzo $(2 \theta=25,50)$ comparadas à placa $100 \%$ argila caulim AC.

A Figura 11 também exibe os perfis de pico para posição angular entre 10,0 e 80,0 para o quartzo, a mulita e a cristobalita para todas as misturas.

A Figura 11 exibe a composição mineralógica de todos os traços de mistura contendo de cristobalita (JCPAS 39-1425) e quartzo (JCPAS 46-1045). A presença da mulita (JCPAS 15-0776), que é resultado da reação ocorrida entre a alumina e a sílica presente na mistura, mostra um aumento proporcional à adição de LETA nas misturas conforme a estequiometria dessa fase cristalina, a qual corresponde a $3 \mathrm{Al}_{2} \mathrm{O}_{3} \cdot 2 \mathrm{SiO}_{2}$.
A inserção de lodo de estação de tratamento nas substituições no traço da mistura AC20 por $10 \%, 20 \%$ e $30 \%$ de lodo de ETA (AC20/10, AC20/20 e AC20/30) gerou um acréscimo de condutividade de $8,69 \%, 30,32 \%$ e $38,30 \%$ respectivamente (Tabela 6). Este aumento na condutividade foi acompanhado de um aumento de porosidade e absorção de água.

A fase "poro" desempenha um papel fundamental no comportamento da irradiação de calor. Em temperaturas abaixo de $800{ }^{\circ} \mathrm{C}$ apresenta comportamento específico. A condução térmica é o mecanismo principal, e os grandes vazios dos poros maiores atuam como barreira ao transporte de calor. Por esta razão, a placa AC20 com a menor absorção de água, dificultando a passagem de calor, apresenta o menor coeficiente de condutividade térmica.

Os ensaios de resistência à compressão mostram um aumento de resistência média à compressão de $171,01 \mathrm{MPa}$ na mistura $\mathrm{AC}$ para 189,97 Mpa na mistura AC20 com variação de, aproximadamente, $11,08 \%$. Este aumento se deve também à presença da sílica da casca de arroz, que tem um efeito significativo no aumento da resistência de materiais cerâmicos em geral, proporcionando uma menor porosidade aparente de $3,93 \% .{ }^{37}$

Conforme ocorreram as substituições na mistura de AC 20 por lodo de estação de tratamento, as placas AC20/10, AC20/20 e AC20/30 mostraram perdas da resistência à compressão de aproximadamente $10,37 \%, 50,84 \%$ e $89,51 \%$, respectivamente.

Neste sentido, mais estudos se fazem necessários na investigação e caracterização da fase "poro" a fim de complementar a interpretação dos dados obtidos, correlacionando os resultados das propriedades físicas, mecânicas e térmicas desenvolvidas das placas cerâmicas em estudo.

\section{Propriedades químicas}

A sílica apresenta-se sob três formas cristalinas: quartzo, tridimita e cristobalita. A cristobalita possui dois arranjos estruturais: fase $\alpha$ (entre $170{ }^{\circ} \mathrm{C}$ e $270{ }^{\circ} \mathrm{C}$ ) e fase $\beta$ acima de $1470{ }^{\circ} \mathrm{C}$. A cristobalita $\beta$ possui menor coeficiente de expansão térmica do que as outras formas de sílica cristalina, além de baixa condutividade térmica e pequeno valor de constante dielétrica. Estes fatores justificam as várias pesquisas que fazem uso da inserção da casca de arroz para estabilizar a temperatura ambiente da fase $\beta$ da cristobalita sem passar para a fase $\alpha$, ou seja, desta forma atuar como um agente dopante de estabilização desta fase. ${ }^{38}$

Este fato justifica o decréscimo de condutividade térmica devido à composição mineralógica à base de cristobalita, bastante intensa nas placas AC20, (Figura 11), que se atribui possivelmente à cristalização da sílica livre proveniente da casca de arroz.

Além disso, apesar da tridimita sofrer transição de fase para cristobalita a $1470{ }^{\circ} \mathrm{C}$ (Figura 12), a ação de óxidos fundentes presentes na mistura possivelmente fomentou a reação de transição de tridimita em cristobalita em temperaturas menores que $1470{ }^{\circ} \mathrm{C}$, proporcionando um aumento ainda maior na fase de cristobalita, mesmo na temperatura de queima das placas de $1300{ }^{\circ} \mathrm{C}$.

Tabela 6. Apresentação dos resultados de ensaios físicos, mecânicos e térmicos

\begin{tabular}{cccccc}
\hline \multirow{2}{*}{ Misturas } & $\begin{array}{c}\text { Absorção de } \\
\text { Água }(\%)\end{array}$ & $\begin{array}{c}\text { Porosidade } \\
\text { Aparente }(\%)\end{array}$ & $\begin{array}{c}\text { Densidade } \\
\left(\mathrm{g} / \mathrm{cm}^{3}\right)\end{array}$ & $\begin{array}{c}\text { Resistência à } \\
\text { compressão }(\mathrm{MPa})\end{array}$ & $\begin{array}{c}\text { Condutividade } \\
\text { térmica }\left(\mathrm{W} \mathrm{m} \mathrm{m}^{-1} \mathrm{~K}^{-1}\right)\end{array}$ \\
\hline AC & $4,92 \pm 0,37$ & $11,31 \pm 5,2$ & $2,13 \pm 0,00$ & $171,01 \pm 6,42$ & $0,2368 \pm 0,006$ \\
AC 20 & $3,93 \pm 0,32$ & $8,9 \pm 3,1$ & $2,27 \pm 0,01$ & $189,97 \pm 3,37$ & $0,2258 \pm 0,002$ \\
AC 20/10 & $4,72 \pm 0,43$ & $10,6 \pm 0,91$ & $2,23 \pm 0,007$ & $172,12 \pm 6,31$ & $0,2574 \pm 0,003$ \\
AC 20/20 & $6,25 \pm 0,22$ & $13,32 \pm 0,40$ & $2,13 \pm 0,01$ & $125,94 \pm 3,6$ & $0,3086 \pm 0,002$ \\
AC 20/30 & $6,65 \pm 0,13$ & $14,11 \pm 0,25$ & $2,12 \pm 0,004$ & $100,24 \pm 2,24$ & $0,328 \pm 0,003$ \\
SL 50/50 & 36,46 & 40,04 & 1,09 & 4,92 & 0,2544 \\
\hline
\end{tabular}




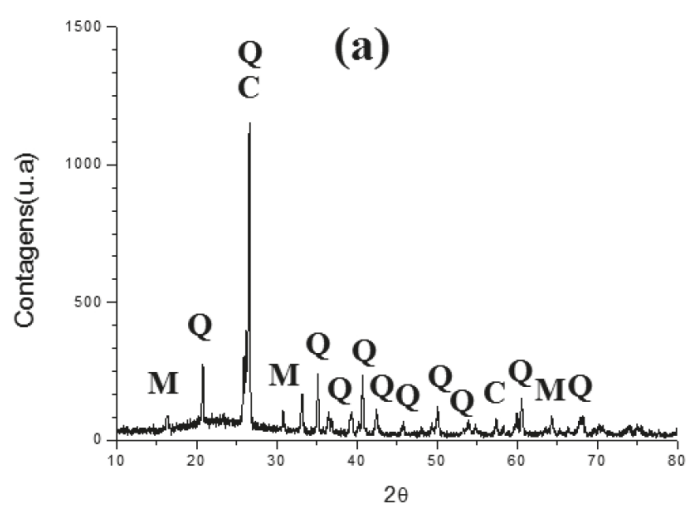

(c)

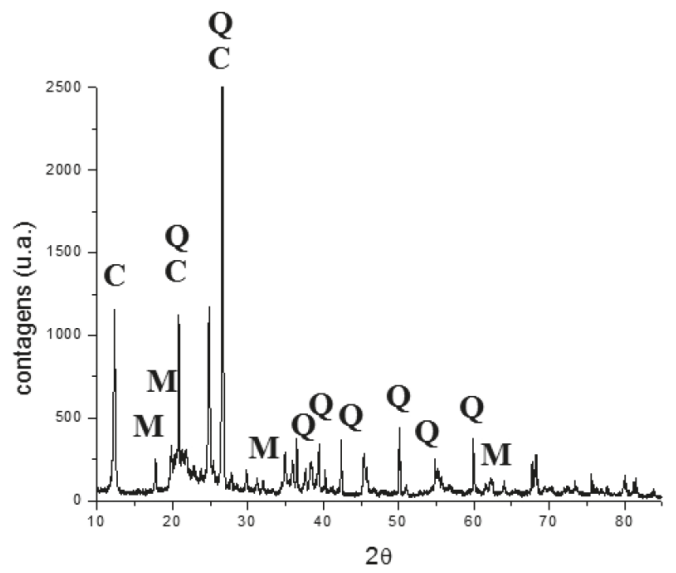

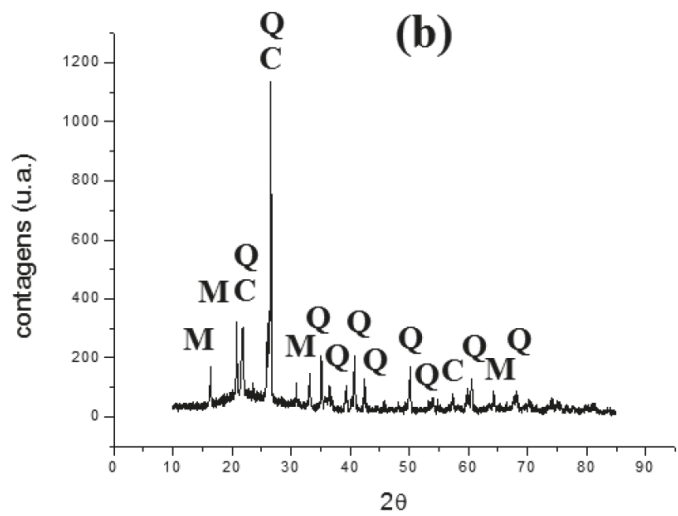

(d)

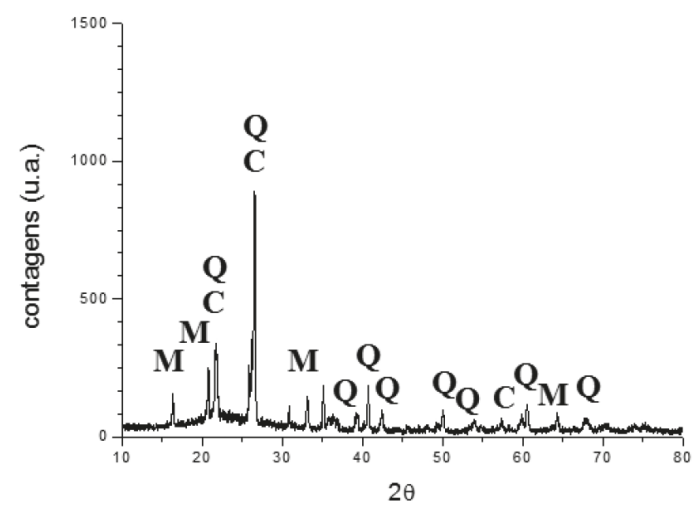

(e)

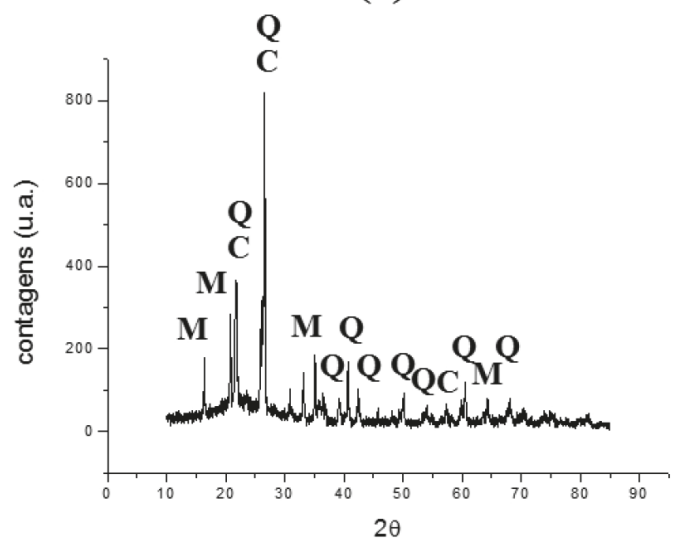

Figura 11. Difratograma das placas cerâmicas (a) AC, (b) AC20, (c) AC20/10, (d) AC20/20 e (e) AC20/30

Um aumento significativo nos picos de mulita foi verificado nas placas que sofreram substituições de lodo de estação de tratamento na mistura AC20 de 10\% (AC20/10), 20\% (AC20/20) e 30\% (AC20/30) devido à incorporação de alumina residual.

O traço com $30 \%$ de substituição de lodo de estação de tratamento (AC20/30) apresenta o pico mais expressivo de formação da fase cristalina de mulita $\left(3 \mathrm{Al}_{2} \mathrm{O}_{3} \cdot 2 \mathrm{SiO}_{2}\right)$ nas posições angulares entre 25,5 e $27,0^{\circ}$, mais especificamente na posição angular de $26,5{ }^{\circ} \mathrm{C}$, devido aos microconstituintes do lodo de estação de tratamento.

A transformação química da caulinita em diferentes temperaturas pode ser representada pelas reações químicas a seguir: ${ }^{38}$

$$
\begin{aligned}
& \mathrm{Al}_{2} \mathrm{Si}_{2} \mathrm{O}_{5}(\mathrm{OH})_{4} \stackrel{450-650^{\circ} \mathrm{C}}{\longrightarrow} \mathrm{Al}_{2} \mathrm{O}_{3} \cdot 2 \mathrm{SiO}_{2}+2 \mathrm{H}_{2} \mathrm{O} \\
& 2\left(\mathrm{Al}_{2} \mathrm{O}_{3} \cdot 2 \mathrm{SiO}_{2}\right) \stackrel{925-1050{ }^{\circ} \mathrm{C}}{\longrightarrow} 2 \mathrm{Al}_{2} \mathrm{O}_{3} \cdot 3 \mathrm{SiO}_{2}+\mathrm{SiO}_{2} \text { (amorfos) } \\
& 3\left(2 \mathrm{Al}_{2} \mathrm{O}_{3} \cdot 3 \mathrm{SiO}_{2}\right) \stackrel{\geq 1050{ }^{\circ} \mathrm{C}}{\longrightarrow} 2\left(3 \mathrm{Al}_{2} \mathrm{O}_{3} \cdot 3 \mathrm{SiO}_{2}\right)+5 \mathrm{SiO}_{2} \\
& \mathrm{SiO}_{2} \text { (amorfos) } \stackrel{\geq 1050^{\circ} \mathrm{C}}{\longrightarrow} \mathrm{SiO}_{2} \text { (Cristobalita) }
\end{aligned}
$$

Chen et $a l .{ }^{39}$ estudaram a obtenção de mulita pela reação de sinterização entre a caulinita e a alumina, e observaram que a alumina permanece inerte até a temperatura de $1200{ }^{\circ} \mathrm{C}$. Já entre $1300{ }^{\circ} \mathrm{C}$ a $1500^{\circ} \mathrm{C}$ a quantidade de mulita aumenta rapidamente pela diminuição da quantidade de alumina.

Além das propriedades químicas, a porosidade específica dos materiais cerâmicos pode exercer influência significativa sobre as 


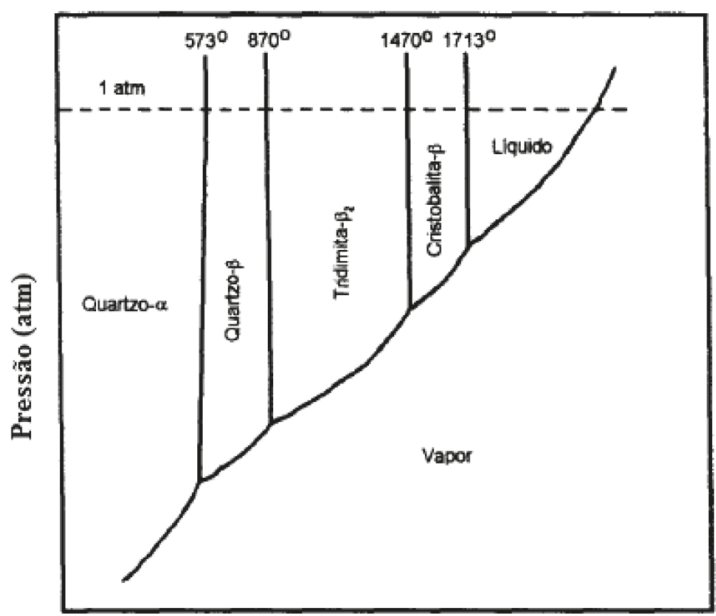

Temperatura $\left({ }^{\circ} \mathrm{C}\right)$

Figura 12. Diagrama de equilíbrio do $\mathrm{SiO}^{38}$

propriedades mecânicas e térmicas destes materiais. ${ }^{37}$ A proporção de poros abertos e/ou fechados proporciona mudanças nas propriedades em geral, uma vez que poros fechados mostram-se inativos quanto ao fluxo de líquidos e de gases, exercendo grande influência sobre as propriedades térmicas.

A presença de poros pode resultar da remoção de elementos da estrutura original, chamado de subtrativo, uma vez que tem lugar quando da saída de gases, durante o aquecimento de um material, ou com a dissolução seletiva de componentes de sólidos multifásicos,

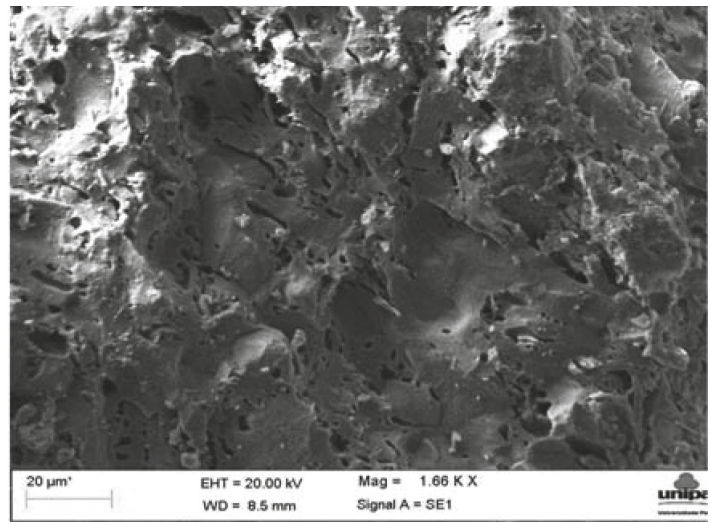

(a) que ocorrem na preparação de vidros, vitrocerâmicas e cerâmicas porosas. $^{40}$

Nesse sentido, mais estudos se fazem necessários na investigação e caracterização da fase "poro" a fim de complementar a interpretação dos dados obtidos, correlacionando os resultados das propriedades físicas, mecânicas e térmicas desenvolvidas das placas cerâmicas em estudo.

\section{Microestrutura}

As imagens da microestrutura interna das placas AC20 (Figura 13-B) mostram uma fase matriz com predominância de uma fase vítrea quando comparada as placas AC (Figura 13-A). Uma maior fase vítrea em presença de óxidos fundentes colabora para o desempenho mecânico do material em função de menor porosidade e menor fissuramento entre os grãos de quartzo, ${ }^{38}$ que justifica que a AC20 possui a menor absorção de água. As principais fases encontradas foram o quartzo e a fase vítrea. A porosidade tende a diminuir no momento em que a matriz vítrea tende a aumentar. ${ }^{40,41}$ Sugere-se que essa menor porosidade aparente ocorre pela facilidade na eliminação dos gases formados na fase líquida durante a sinterização.

As substituições em AC20 por $10 \%$ e $30 \%$ com lodo de ETA, conforme Figura 14, mostra uma menor fase vítrea, um volume maior de poros relacionado com a elevação da taxa de substituição. Nota-se também a presença de poros alongados, distribuição irregular e uma maior concentração de poros interligados aprisionados na fase vítrea. Sugere-se que essa maior porosidade aparente ocorre pela queima dos argilominerais e da matéria orgânica durante a sinterização. Estas placas apresentam as fases cristalinas predominando o quartzo, a

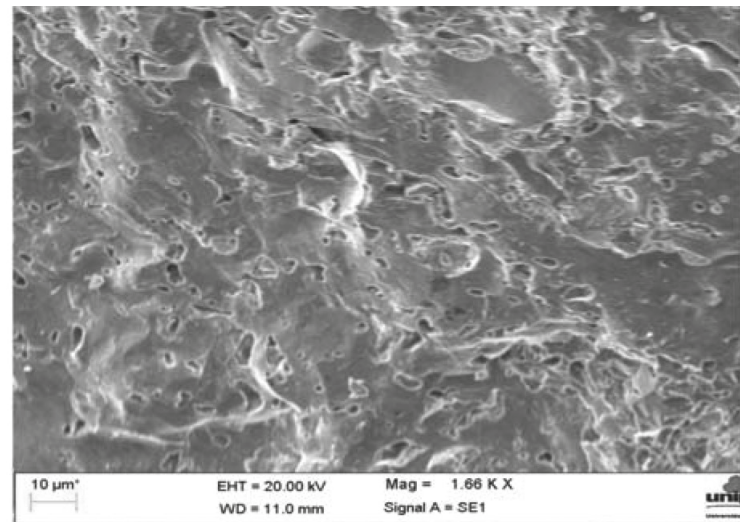

(b)

Figura 13. Microscopia eletrônica de varredura da superfície de ruptura: (a) AC (100\% argila caulim); (b) AC 20 (80\% argila caulim e 20\% sílica da casca de arroz)

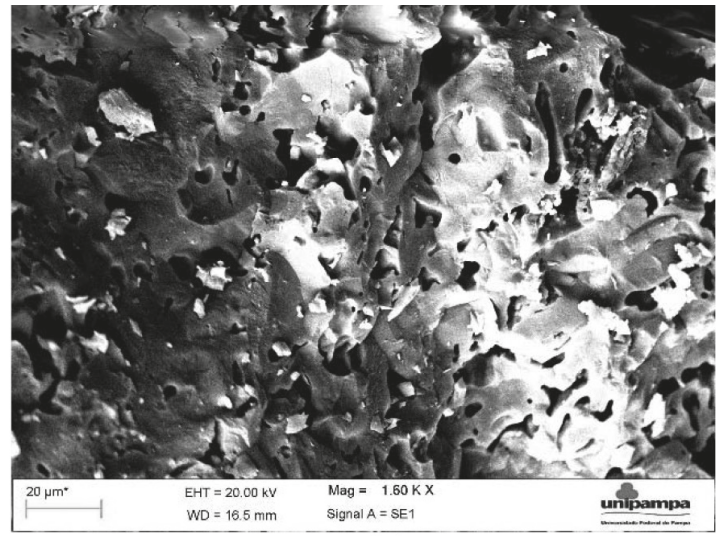

(a)

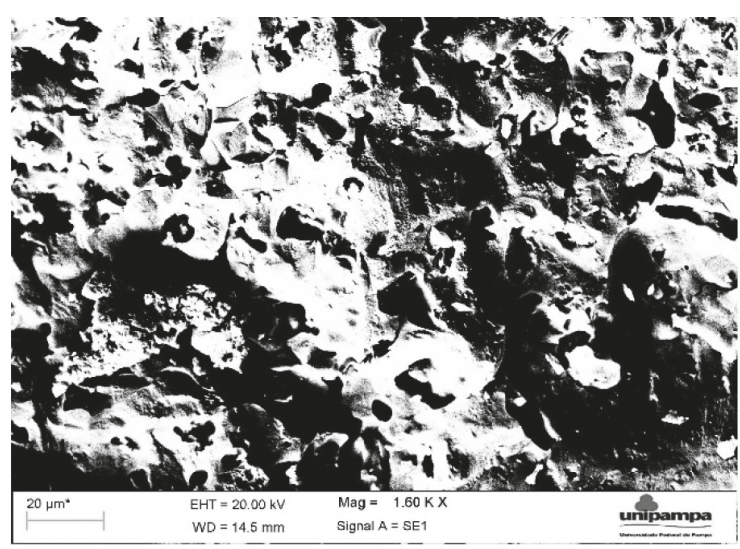

(b)

Figura 14. Fotomicrográficas em MEV da superfície de ruptura: (a) AC 20/10 (10\% LETA); (b) AC 20/30 (30\% LETA) 
mulita e a cristobalita, além de uma a microestrutura com uma fase porosa bastante disseminada com poros maiores e mais alongados.

\section{CONCLUSÕES}

Com base nos resultados obtidos a partir dos ensaios realizados nas placas cerâmicas produzidas, as principais conclusões são:

a) Placas cerâmicas prensadas podem ser obtidas a partir da sílica residual da casca de arroz e do lodo de ETA, valorizando e direcionando o descarte desses resíduos, contemplando o reaproveitamento de resíduos e geração de novos produtos de engenharia;

b) As placas cerâmicas contendo $80 \%$ argila caulim e $20 \%$ sílica de casca de arroz (AC20) apresentaram maior fase vítrea, menor condutividade térmica, menor concentração de poros e maior resistência mecânica devido aos tamanhos das partículas de sílica e argila caulim que propiciam o acomodamento irregular destas, conforme imagens obtidas por microscopia eletrônica de varredura;

c) As placas cerâmicas contendo 64\% argila caulim, 16\% sílica de casca de arroz e 20\% ETA (AC20/10) foram as que contemplaram todos os itens de reaproveitamento dos resíduos do lodo de estação de tratamento e sílica da casca de arroz, simultaneamente às boas propriedades termomecânicas com 172,12 Mpa de resistência à compressão e $0,2574 \mathrm{~W} \mathrm{~m}^{-1} \mathrm{~K}^{-1}$ de condutividade térmica.

d) Nas análises obtidas através da difração de raios X observou-se um aumento expressivo na formação da fase cristalina da mulita $\left(3 \mathrm{Al}_{2} \mathrm{O}_{3} \cdot 2 \mathrm{SiO}_{2}\right)$ nas placas cerâmicas com substituição de lodo de ETA em sua mistura (AC20/10, AC20/20, AC20/30) provavelmente devido à presença de alumina residual na composição química do lodo de ETA. O traço AC20/30 apresentou o pico mais expressivo de mulita, além das fases cristalinas de quartzo e de cristobalita, provavelmente em função da maior quantidade dos microconstituintes do lodo de ETA.

\section{AGRADECIMENTOS}

Ao CNPQ pelo suporte financeiro Projeto 423453 2016-5 e ao LEME - Laboratório de Ensaios e Modelos Estruturais.

\section{REFERÊNCIAS}

1. Fungaro, D. A.; Yamaura, M.; Carvalho, T. E. M.; Journal of Atomic and Molecular Sciences 2011, 2, 305.

2. http://irga.rs.gov.br/estimativa-de-plantio-para-safra-2016-2017-e-de-1086-milhao-de-hectares, acessado em setembro de 2018.

3. Della, V. P.; Kuhn, I.; Hotza, D.; Revista Cerâmica Industrial 2005, 10, 22.

4. Hoppe, A. E.; Dissertação de Mestrado, Universidade Federal de Santa Maria, Brasil, 2008.

5. Nehdi, J. M.; Duquette, A.; Damatty, E.; Cem. Concr. Res. 2003, 33, 1203.

6. Salas, A.; Delvasto, S.; Gutierrez, R. M., Lange, D.; Cem. Concr. Res. 2009, 39, 773

7. Trindade, E. C.; Pio, E. S.; Silva, T. M. V.; Faour, E. C.; Spengler, R. L.; Grosser, F. N.; Schmidt, A. M.; Tamborim, S. M.; Adv. Civ. Eng. Mater. 2016, 5, 195

8. Krishnarao, R. V.; Mahajan, Y. R.; J. Ceram. Int. 1996, 22, 353.

9. Chareonpanich, M.; Namto, T.; Kongkachuichay, P.; Limtrakul, J.; Fuel Process. Technol. 2004, 85, 1623.

10. Feng, Q.; Lin, Q., Gong, F.; Sugita, S.; Shoya, M.; J. Colloid Interface Sci. 2004, 278, 1

11. Foletto, E. L.; Hoffmann, R.; Hoffmann, R. S.; Portugal Jr., U. L.; Jahn, S. L.; Quim. Nova 2005, 28, 1055
12. Guzman, A.; Delvasto, S.; Quereda, M. F.; Sanchez, E.; Cerâmica 2015, 61,442

13. Liou, T. H.; Yang, C. C.; Mater. Sci. Eng. 2011, B-176, 521

14. Singh, D.; Kumar, Rai, K. N.; Ceramic 2008, 54, 203

15. Menezes, R. R.; Fagury-Neto, F.; Fernandes, M. C.; Souto, P. M.; Kiminami, G. A.; Cerâmica 2008, 54, 245

16. Silva, M. V.; Dissertação de mestrado, Universidade de São Paulo, Brasil, 2011.

17. Hamoda, M. F.; Desalination 2004, 164, 203.

18. Associação Brasileira de Normas Técnicas, NBR 10004: Resíduos sólidos - classificação, Rio de Janeiro, 2004.

19. Tallini Junior, V. M.; Dissertação de Mestrado, Universidade Federal do Paraná, Brasil, 2009.

20. Huang, C; Pan, J. R; Sun, K.-D; Liaw, C.-T.; Water Sci. Technol. 2001 , 44, 273.

21. Paixão, L. C. C.; Dissertação de Mestrado, Universidade Federal de Ouro Preto, Brasil, 2005

22. Hoppen, C.; Portella, K. F.; Jouskoski, A.; Trindade, E. M.; Andreóli, C.; Quim. Nova 2006, 21, 79.

23. Botero, W. G.; Santos, A.; Oliveira, L. C.; Rocha, J. C.; Quim. Nova 2009, 32, 2018.

24. Associação Brasileira de Normas Técnicas, NBR 9644: Preparação de amostras para análise química de materiais refratários, ABNT, 1986, p. 16.

25. Associação Brasileira de Normas Técnicas, NBR 12860: Materiais refratários magnesianos - Análise química por espectrometria de fluorescência de raios X, ABNT, 1993.

26. Bragança, S. R.; Bergman, C. P.; Rev. Cerâmica 2004, 50, 291.

27. Angel, J. D. M.; Vásquez, T. G. P.; Junkes, J. A.; Hotza, D.; Quim. Nova 2009, 32, 1110 .

28. Armesto, L.; Bahillo, A.; Veijonen, K.; Cabanillas, A.; Otero, J.; Biomass Bioenergy 2002, 23, 171.

29. Rozainee, M.; Ngo, S. P.; Salema, A. A.; Tan, K. G.; Ariffin, M.; Zainura, Z. N.; Bioresour. Technol. 2007, 99, 703.

30. Associação Brasileira de Normas Técnicas, NBR 10237: Materiais refratários - Classificação. Rio de Janeiro, 2001.

31. Associação Brasileira de Normas Técnicas, NBR 7181: Solos - Análise granulométrica. Rio de Janeiro, 1984.

32. Fouateu, R. Y.; Ndimukong, F.; Njoya, A.; Kunyukubundo, F.; Mbih, P. K.; Journal of Asian Ceramic Societies 2016, 4, 299

33. Oliveira, F. M. S.; Machado, S. O.; Holanda, J. N. F.; Ceramic 2004, 50, 324

34. Associação Brasileira de Normas Técnicas, NBR 6220: Materiais refratários densos conformados — Determinação do volume aparente, densidade de massa aparente, porosidade aparente, absorção e densidade aparente da parte sólida. Rio de Janeiro, 2011.

35. Associação Brasileira de Normas Técnicas, NBR 6224: Materiais refratários densos conformados - Determinação da resistência a compressão a temperatura ambiente. Rio de Janeiro, 2001.

36. Norma DIN EN12667 - Desempenho térmico de materiais e produtos de construção - Determinação da resistência térmica por meio de métodos de medição e medidor de fluxo de calor protegidos - Produtos de alta e média resistência térmica Versão alemã EN 12667: 2001.

37. Gonçalves, M. R. F.; Bergmann, C. P.; Cerâmica Industrial 2006, 11, 38

38. Harima, E.; Dissertação de mestrado, Universidade Federal de São Paulo, Brasil, 1997.

39. Chen, C. Y; Lan, G. S; Tuan, W. H.; J. Eur. Ceram. Soc. 2000, 30, 2519.

40. Menezes, R. R.; Fagury-Neto, F.; Fernandes, M. C.; Souto, P. M.; Kiminami, G. A.; Cerâmica 2008, 54, 245.

41. Nara, E. O. B.; Moraes, J. A. R.; Freitas, A. M. V.; Rediske, G.; Benitez, G. B.; Cerâmica 2014, 60, 340. 